\title{
Comprehensive evaluation and dynamic evolution analysis of urban vulnerability of old industrial bases in Heilongjiang Province, China
}

\author{
Jingyuan YUAN, School of Architecture, Harbin Institute of Technology; Key Laboratory of Cold Region \\ Urban and Rural Human Settlement Environment Science and Technology, Ministry of Industry and \\ Information Technology, China
}

Yuze LI, School of Architecture, Harbin Institute of Technology; Key Laboratory of Cold Region Urban and

Rural Human Settlement Environment Science and Technology, Ministry of Industry and Information Technology, China

Xiaoguang LIU, School of Architecture, Harbin Institute of Technology; Key Laboratory of Cold Region Urban and Rural Human Settlement Environment Science and Technology, Ministry of Industry and Information Technology, China

\begin{abstract}
Urban vulnerability has always been the main component of urban planning research, and it is an important basis for judging whether urban development is healthy and sustainable. As the largest old industrial bases in the country, northeast China has embarked on a development path dominated by heavy industry under the planned economy system. Its industrial structure is not sustainable, and it requires long-term reliance on natural resources. The ecological environment has been destroyed. Studying the urban vulnerability of old industrial bases in northeast China is of great significance for their revitalization as well as the promotion of high-quality urban development in China. Using 12 prefecture-level cities in the Heilongjiang Province in northeast China as the research subjects, an evaluation index system was constructed from four subsystems: ecological environment, resources, society, and economy. The spatial pattern and dynamic evolution of urban vulnerability from 2010 to 2019 were analyzed using the entropy method, comprehensive index method, and grey relational grade. The results were as follows. (1) Spatially, the urban vulnerability pattern of Heilongjiang Province in 2015 showed clustering of highvulnerability areas, and then the overall urban vulnerability decreased and tended to be evenly distributed. (2) In terms of time, the urban vulnerability of Heilongjiang Province showed an upward trend from 2010 to 2013 and gradually decreased from 2013 to 2019. Resource vulnerability, ecological vulnerability, and social vulnerability steadily decreased, whereas economic vulnerability first increased and then decreased. (3) The correlation between urban comprehensive vulnerability and ecological vulnerability in Heilongjiang Province was the highest in 2010, and the correlation between urban vulnerability and economic vulnerability was the highest in 2013-2015, and then the correlation shifted to social vulnerability. In the future, during the revitalization of the old industrial bases, Heilongjiang Province should strengthen economic transformation, optimize the industrial structure, strengthen ecological civilization, and improve the utilization rate of resources.
\end{abstract}

\section{Keywords}

Urban vulnerability, Old industrial base, Spatial autocorrelation analysis, Grey correlation analysis 


\section{The introduction}

In the 1970s, the concept of "vulnerability" was introduced into the field of natural disasters(Turner et al., 2003) and then gradually extended to the field of social sciences(He and Zhang, 2011). Urban vulnerability is an extension of traditional vulnerability research in the field of city planning (Zhang et al., 2015, Fang et al., 2016). However, urban vulnerability is different, and the ability to resist interference is also different. As a complex system coupled with ecological, resource, social, and economic subsystems, the change in the vulnerability of any subsystem will lead to a change in urban vulnerability. Therefore, urban vulnerability needs to be subdivided into ecological vulnerability, resource vulnerability, social vulnerability, and economic vulnerability from the perspective of coupling. It is of theoretical and practical significance to analyze subsystem vulnerability of the city, study the development status of the city, convert findings into decision-making information, and relate feedback to the decision-makers and planners of urban development. This is essential to the future development mode of the city and the quality of life of its people. Studies on vulnerability at home and abroad have mainly focused on exploring the connotation of vulnerability (Vogel, 2004, Adger et al., 2006), the construction of a conceptual vulnerability model (Lee, 2014, Wang et al., 2013, FERDINANDO et al., 2002) and overall vulnerability assessment (Bo et al., 2015, Lin et al., 2014). The existing research results provide scientific theoretical support for expanding the study of urban vulnerability. In recent years, Chinese scholars have researched resource cities and coastal cities in domains such as urban vulnerability and its dynamic evolution process, and dynamic studies of urban vulnerability have already been completed(Yu, 2014, Mei et al., 2018, Yanzhong et al., 2020). However, there are still some deficiencies in the study of the urban vulnerability of old industrial bases. The evaluation system in the existing research is insufficient. Furthermore, the scope of the evaluation method is limited, and it does not represent the urban vulnerability of old industrial bases that depends on the development of heavy industry.

Therefore, from the perspective of coupling, this study comprehensively evaluated the urban vulnerability of Heilongjiang Province in 2010, 2013, 2015, 2017, and 2019, and analyzed the urban vulnerability from the whole, temporal, spatial, and subsystem perspectives. In the second part of this study, the study area and data sources are briefly introduced. In the third part, an urban vulnerability evaluation model is constructed, and the evaluation results are analyzed in the fourth part. In the fifth part, the urban vulnerability analysis conclusion and urban development suggestions are presented. 


\section{Research area and data sources}

\subsection{Study area overview}

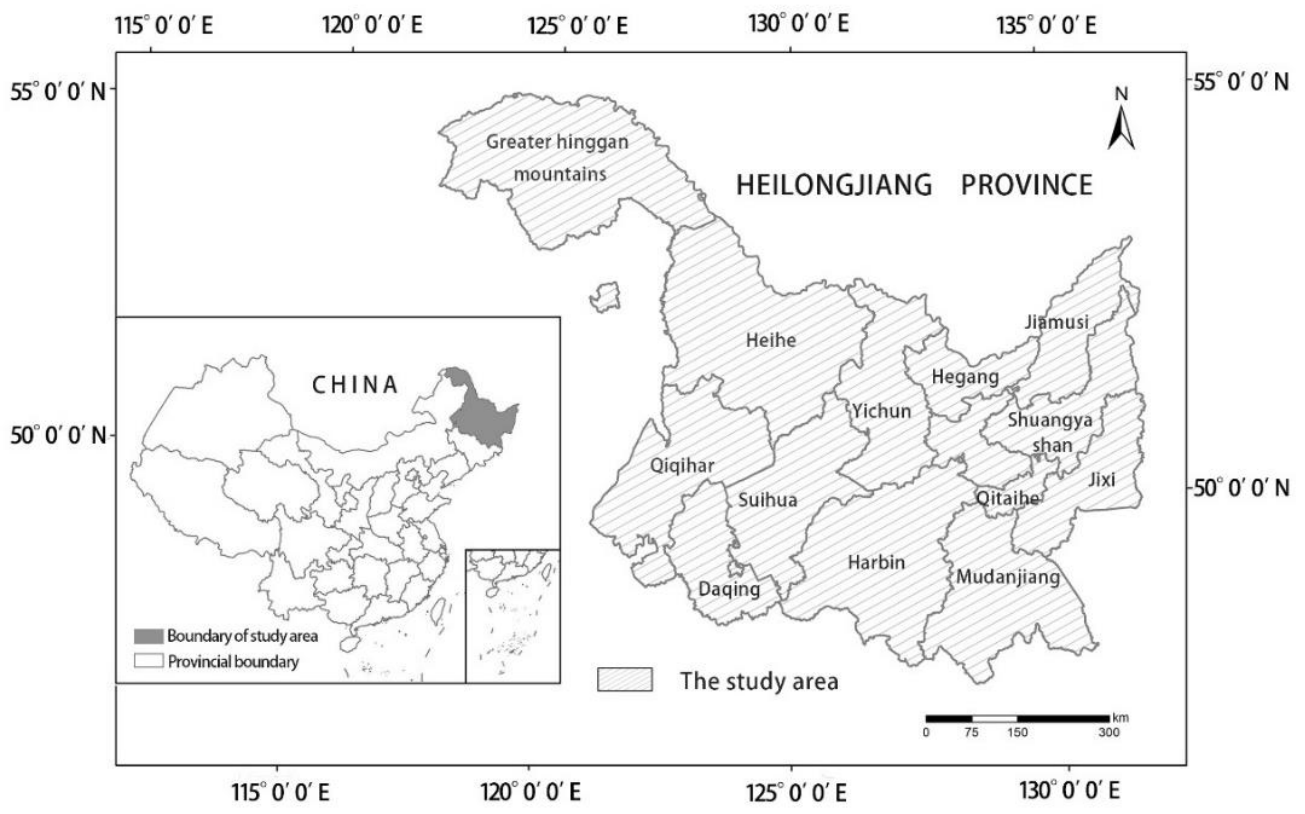

Figure 1 Location map of the study area. Source: Authors, 2021.

The study area is located in northeast China, within $121^{\circ} 11^{\prime}-135^{\circ} 05^{\prime} \mathrm{E}, 43^{\circ} 26^{\prime}-53^{\circ} 33^{\prime} \mathrm{N}$. The administrative area covers $473,000 \mathrm{~km}^{2}$. It is the northernmost provincial administrative region of China. Heilongjiang Province borders Russia to the east and north, and Inner Mongolia and Jilin Province to the west and south. As one of the earliest old industrial bases in China, it has embarked on a road of economic development dominated by heavy industry under the traditional Chinese economic system.

\subsection{Data sources}

The research data in this study included social, economic, resource, and environmental basic data for cities in Heilongjiang Province during 2010, 2013, 2015, 2017, and 2019. The basic data are mainly from the "Statistical Yearbook of Chinese Cities," the "Statistical Yearbook of Heilongjiang Province, "Heilongjiang Province city social and economic statistics yearbooks, and other statistical data. The data for the Great Khingan Mountains and Daxinganling area in Heilongjiang Province are missing because of the long periods with incomplete statistics; thus, the evaluation and analysis for these areas were not included in this study. The urban spatial data of Heilongjiang Province used in this study were obtained from the National Basic Geographic Database. Basic data processing and analyses were performed using Microsoft Excel and SPSS. Spatial data analysis and visualization were performed using GeoDa software and ArcGIS Pro2.7 software.

\section{Index system and evaluation model}

\subsection{Index system construction}

At present, research on the vulnerability of industrial cities dominated by heavy industry is still insufficient, and the vulnerability evaluation index system of industrial cities is incomplete. Therefore, based on the principles of science, systematics, and availability, the evaluation index system for urban vulnerability was improved while referring to the existing research results(Yanzhong et al., 2020, Wei-ke, 2020, Haining et al., 2018). The relevant indexes characterizing the urban characteristics of old industrial bases were added. Using the prefecture-level cities of Heilongjiang Province during five periods as the research subjects, 35 
evaluation indexes in four areas, including resources, ecology, society, and economy, were selected to form the vulnerability evaluation index system of heavy industry cities.

\subsection{Evaluation model construction}

(1) Data standardization

Urban vulnerability evaluation factors have different evaluation dimensions and orders of magnitude. To eliminate the influence of the index dimensions, it is necessary to standardize the basic data. When the index is larger and city vulnerability is higher, the index is positive, such as the comprehensive energy consumption of industrial enterprises and the proportion of secondary production to gross domestic product (GDP). Negative indicators are opposite, such as sewage treatment rate and natural gas penetration rate. The greater the negative indicators, the lower the degree of urban vulnerability. Positive and negative evaluation indicators have opposite effects on urban vulnerability, such that positive and negative indicators are standardized according to Equation 1 and Equation 2, respectively.

$$
\chi_{i j}=\frac{X_{i j}-\min \left\{X_{i j}\right\}}{\max \left\{X_{i_{j}}\right\}-\min \left\{X_{i j}\right\}}
$$

Equation 1

$$
x_{i j}=\frac{\max \left\{X_{i j}\right\}-X_{i j}}{\max \left\{X_{i j}\right\}-\min \left\{X_{i j}\right\}}
$$

Equation 2

In the equation: $x_{i j}$ is the standardized value of each evaluation index; $X_{i j}$ is the original data of evaluation index.

(2) Index weight determination

To avoid the subjectivity of weight assignment and ensure its scientific objectivity, the entropy method, which can represent the degree of disorder of index information, was selected to determine the weight of the evaluation index. As an objective weighting method, the entropy method discriminates the weight coefficient according to the degree of disorder of the index information. The less useful information an index contains, the higher the information entropy and the smaller the weight. Conversely, the smaller the information entropy, the higher the weight of the coefficient of the index. We calculated the weight using the entropy method according to Equation 3, Equation 4, and Equation 5:

Equation 3

$$
y_{i j}=\frac{x_{i j}}{\sum_{j=1}^{m} x_{i j}}\left(0<y_{i j} \leq 1\right)
$$

Equation 4

$$
e_{j}=-\frac{\sum_{i=1}^{m} y_{i j} \ln y_{i j}}{\ln m}
$$

$$
w_{i}=\frac{1-e_{j}}{\sum_{i=1}^{n}\left(1-e_{j}\right)}
$$

Equation 5

The weight of each index in the urban vulnerability assessment system of Heilongjiang Province was obtained using the calculations above (Table 1 ). 
Table 1 Urban vulnerability evaluation Index System for Heilongjiang Province. Source: Authors, 2021.

\begin{tabular}{|c|c|c|c|c|c|}
\hline $\begin{array}{l}\text { Elements } \\
\text { layer }\end{array}$ & Rule layer & Index layer & Unit & Index type & Weight \\
\hline \multirow{7}{*}{$\begin{array}{c}\text { Resource } \\
\text { vulnerability }\end{array}$} & \multirow{4}{*}{$\begin{array}{l}\text { Resource } \\
\text { sensitivity }\end{array}$} & $\begin{array}{l}\text { Electricity consumption per unit } \\
\text { of GDP }\end{array}$ & KWh/10,000 yuan & + & 0.0356 \\
\hline & & $\begin{array}{l}\text { Water consumption per unit of } \\
\text { GDP }\end{array}$ & $\mathrm{m}^{3} / 10,000$ yuan & + & 0.0487 \\
\hline & & $\begin{array}{l}\text { Energy consumption per unit of } \\
\text { GDP }\end{array}$ & $\begin{array}{c}\text { T Standard } \\
\text { coal/10,000 yuan }\end{array}$ & + & 0.0264 \\
\hline & & $\begin{array}{l}\text { Comprehensive energy } \\
\text { consumption of industrial } \\
\text { enterprises }\end{array}$ & $\begin{array}{l}\text { Tons of standard } \\
\text { coal }\end{array}$ & + & 0.0681 \\
\hline & $\begin{array}{c}\text { Resource } \\
\text { adaptability }\end{array}$ & $\begin{array}{l}\text { Per capita daily domestic water } \\
\text { consumption }\end{array}$ & I & + & 0.0234 \\
\hline & \multirow{2}{*}{$\begin{array}{l}\text { Resource } \\
\text { resilience }\end{array}$} & Natural gas penetration & $\%$ & - & 0.0223 \\
\hline & & Water penetration rate & $\%$ & - & 0.0312 \\
\hline \multirow{9}{*}{$\begin{array}{c}\text { Ecological } \\
\text { vulnerability }\end{array}$} & \multirow{3}{*}{$\begin{array}{l}\text { Ecological } \\
\text { sensitivity }\end{array}$} & $\begin{array}{l}\text { Discharge of industrial } \\
\text { wastewater }\end{array}$ & $10^{4} t$ & + & 0.0501 \\
\hline & & Industrial soot emission & $10^{4} \mathrm{t}$ & + & 0.0577 \\
\hline & & $\begin{array}{l}\text { Industrial sulfur dioxide } \\
\text { emissions }\end{array}$ & $10^{4} t$ & + & 0.0528 \\
\hline & \multirow{3}{*}{$\begin{array}{l}\text { Ecological } \\
\text { adaptation }\end{array}$} & Sewage treatment rate & $\%$ & - & 0.0552 \\
\hline & & $\begin{array}{c}\text { Garbage harmless treatment } \\
\text { rate }\end{array}$ & $\%$ & - & 0.0026 \\
\hline & & $\begin{array}{c}\text { Comprehensive utilization rate } \\
\text { of industrial solid waste }\end{array}$ & $\%$ & - & 0.0775 \\
\hline & \multirow{3}{*}{$\begin{array}{l}\text { Ecological } \\
\text { resilience }\end{array}$} & $\begin{array}{l}\text { Afforestation coverage rate of } \\
\text { built-up area }\end{array}$ & $\%$ & - & 0.0433 \\
\hline & & Per capita park green area & $\mathrm{m}^{2}$ & - & 0.007 \\
\hline & & $\begin{array}{l}\text { Government spending on } \\
\text { environmental protection and } \\
\text { energy conservation }\end{array}$ & $\begin{array}{l}\text { Ten thousand } \\
\text { yuan }\end{array}$ & - & 0.0048 \\
\hline \multirow{4}{*}{$\begin{array}{c}\text { Social } \\
\text { vulnerability }\end{array}$} & \multirow{4}{*}{$\begin{array}{c}\text { Social } \\
\text { sensitivity }\end{array}$} & $\begin{array}{c}\text { Registered urban unemployment } \\
\text { rate }\end{array}$ & $\%$ & + & 0.0173 \\
\hline & & Urban population density & People $/ \mathrm{km}^{3}$ & + & 0.0173 \\
\hline & & Per capita construction land & $\mathrm{m}^{2} /$ People & + & 0.041 \\
\hline & & $\begin{array}{c}\text { Proportion of secondary industry } \\
\text { employees }\end{array}$ & $\%$ & + & 0.0326 \\
\hline
\end{tabular}




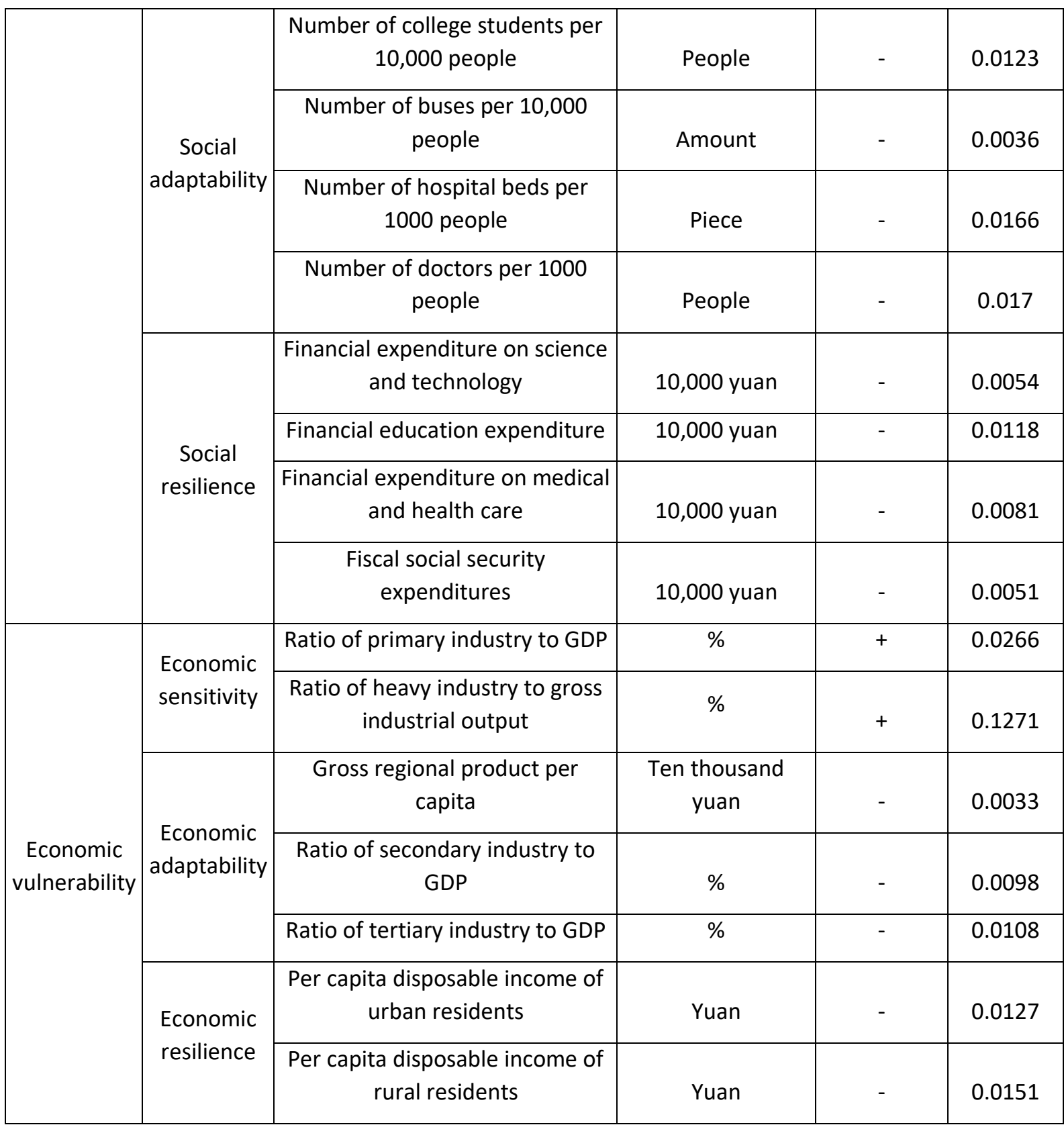

(3) Calculation of urban vulnerability index

A comprehensive index method was adopted to calculate the comprehensive vulnerability of the city. The index data after the standardized processing were multiplied by the weight determined by the entropy method, and all the results were summed to obtain the urban vulnerability index for the city. The urban vulnerability index for the city was calculated using Equation 6:

\section{Equation 6}

$$
U V I=\sum_{j=1}^{n}\left(w_{i} \times x_{i j}\right) \quad i=1,2 \ldots m
$$

In the equation, wi is the weight coefficient of item I, and X ij is the standardized value of item I.

(4) Urban vulnerability classification

Based on the existing research results, the urban vulnerability of Heilongjiang Province was divided into five grades according to the urban vulnerability index. The urban vulnerability index had slight vulnerability 
at $0-0.20$, low vulnerability at $0.20-0.40$, moderate vulnerability at $0.40-0.60$, high vulnerability at $0.60-$ 0.80 , and extreme vulnerability at $0.80-1.00$ (Table 2 ).

Table 2 Urban vulnerability assessment grading standard of Heilongjiang Province. Source: Authors, 2021.

\begin{tabular}{|l|l|l|l|l|l|}
\hline $\begin{array}{l}\text { Vulnerability } \\
\text { composite } \\
\text { index }\end{array}$ & {$[0,0.20)$} & {$[0.20,0.40)$} & {$[0.40,0.60)$} & {$[0.60,0.80)$} & {$[0.80,1.00)$} \\
\hline $\begin{array}{l}\text { Vulnerability } \\
\text { degree }\end{array}$ & $\begin{array}{l}\text { Micro } \\
\text { vulnerable }\end{array}$ & Low vulnerable & $\begin{array}{l}\text { Moderately } \\
\text { vulnerable }\end{array}$ & $\begin{array}{l}\text { High } \\
\text { vulnerability }\end{array}$ & $\begin{array}{l}\text { Extremely } \\
\text { vulnerable }\end{array}$ \\
\hline
\end{tabular}

(5) Spatial autocorrelation analysis

Spatial autocorrelation analysis reveals interdependent and interrelated relationships between adjacent geographical units in a certain attribute in space. In this study, Moran's index (Moran's I) was used to characterize whether there was spatial autocorrelation in the urban vulnerability of cities in the study area. The range of values of Moran's I is -1 to 1 . When it is greater than 0 , it indicates a positive spatial correlation, and the closer it is to 1 , the stronger the correlation. When it is less than 0 , it indicates a negative spatial correlation. As Moran's I approaches -1 , the strength of the negative spatial correlation increases.

(6) Grey correlation analysis

Grey correlation analysis is a method to measure the degree of correlation between different systems according to the degree of similarity or dissimilarity of their developmental trends. In this study, the urban vulnerability index was used as the reference series, and the vulnerability indexes of the ecological, resource, social, and economic subsystems were used as the comparison series, and the grey correlation degree analysis was conducted.

\section{Spatial-temporal evolution analysis of urban vulnerability}

Table 3 Urban vulnerability Index of Heilongjiang Province from 2010 to 2019. Source: Authors, 2021.

\begin{tabular}{|c|c|c|c|c|c|}
\hline City $\quad$ Year & 2010 & 2013 & 2015 & 2017 & 2019 \\
\hline Harbin & 0.363577 & 0.441948 & 0.374269 & 0.234397 & 0.208803 \\
\hline Qiqihar & 0.385329 & 0.428373 & 0.473 & 0.303184 & 0.280641 \\
\hline Jixi & 0.412248 & 0.514896 & 0.527105 & 0.361344 & 0.31017 \\
\hline Hegang & 0.370934 & 0.476119 & 0.429704 & 0.35589 & 0.27668 \\
\hline Shuangya shan & 0.458914 & 0.440644 & 0.462222 & 0.333587 & 0.336582 \\
\hline Daqing & 0.458643 & 0.486496 & 0.408664 & 0.373835 & 0.309178 \\
\hline Yichun & 0.390038 & 0.448916 & 0.4235 & 0.386757 & 0.356592 \\
\hline Jiamusi & 0.370589 & 0.39653 & 0.423078 & 0.265229 & 0.236636 \\
\hline Qitaihe & 0.416844 & 0.492773 & 0.455123 & 0.329802 & 0.29724 \\
\hline Mudanjiang & 0.3835 & 0.438536 & 0.405464 & 0.304689 & 0.262148 \\
\hline Heihe & 0.304607 & 0.419637 & 0.316867 & 0.276916 & 0.230337 \\
\hline Suihua & 0.369238 & 0.401088 & 0.394618 & 0.313374 & 0.286313 \\
\hline
\end{tabular}


(a) 2010

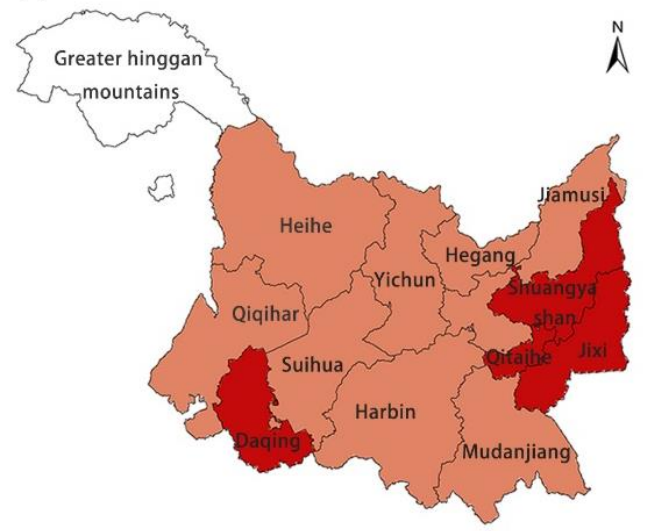

(c) 2015

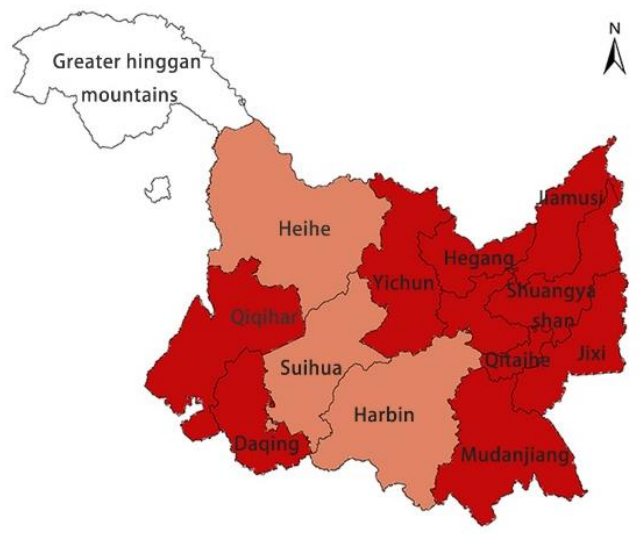

(e) 2019

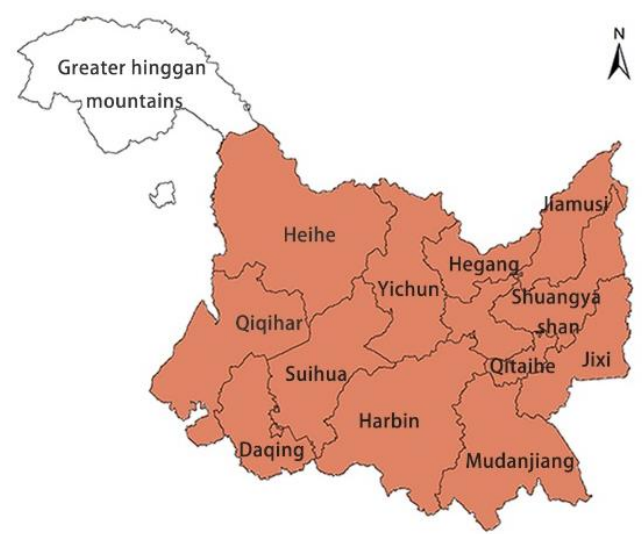

(b) 2013

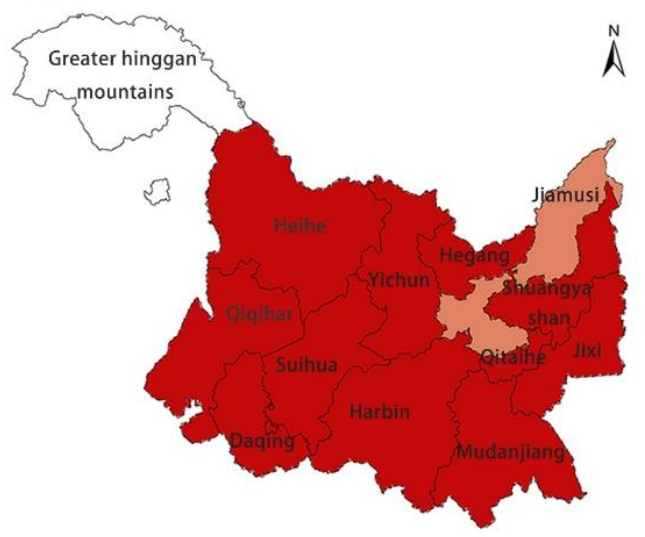

(d) 2017

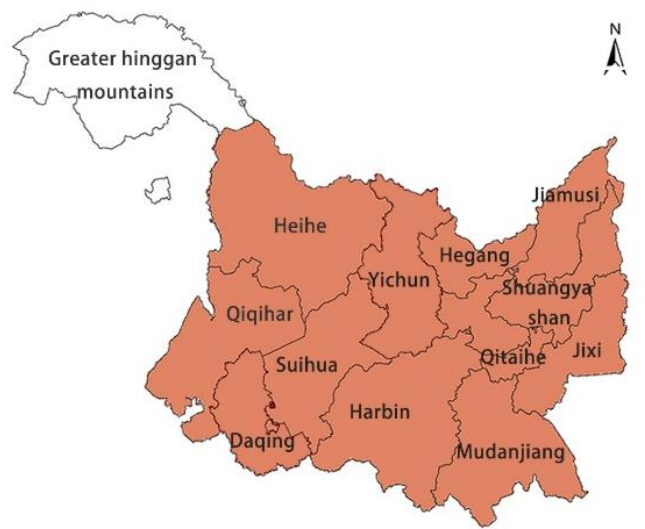

Legend

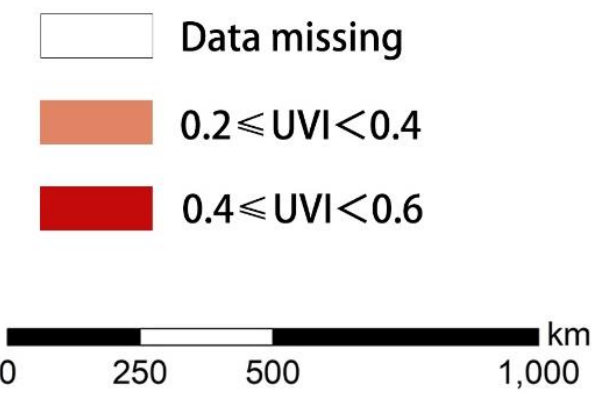

Figure 2 Urban vulnerability level of Heilongjiang Province from 2010 to 2019. Source: Authors, 2021.

The urban vulnerability index of 12 prefecture-level cities in Heilongjiang Province at the temporal scale of 5 years was calculated (Table 3). According to the classification of urban vulnerability, spatial analysis, and the grey correlation analysis were used to analyze the spatial and temporal dynamic evolution of urban vulnerability in Heilongjiang Province over 10 years. According to the urban vulnerability assessment grading standard of Heilongjiang Province, the urban vulnerability comprehensive index of prefecture-level cities in Table 3 was graded. ArcGIS software was used for visual processing (Figure 2).

\subsection{Overall urban vulnerability analysis}

Table 3 shows differences in vulnerability among the 12 prefecture-level cities in Heilongjiang Province, and the overall vulnerability shifted from moderate to low, exhibiting a trend of a "slight increase to a 
steady decline." In 2010, the urban vulnerability composite index of Jixi, Shuangyashan, Daqing, and Qitaihe was relatively high and at the moderate vulnerability level. The ecological environment of these four cities was depleted, the industrial structure was single and unsustainable, and the industrial development was mainly dependent on energy exploitation, which led to the increased vulnerability of the resource subsystem in the city. In 2013, the urban vulnerability index of Heilongjiang Province continued to rise, except in Jiamusi, which was still at a low vulnerability level. All other cities were at a moderate vulnerability level. The vulnerability of Jixi and Qitaihe was the highest, mainly because of the decrease in the proportion of secondary and tertiary industries in the GDP, the significant increase in the proportion of heavy industry, and the increased dependence of urban development on heavy industry, leading to a significant increase in the vulnerability of the economic subsystem. This situation was somewhat improved in 2015 . The comprehensive vulnerability index of Qiqihar, Jixi, and Jiamusi increased, whereas most cities exhibited a slight decrease. As can be seen from Figure 2, from 2017 to 2019, the comprehensive vulnerability indexes of cities at the local level all showed a downward trend, and the vulnerability grades all decreased to low vulnerability. The comprehensive and resource vulnerability indexes of Daqing and Yichun were relatively higher than those of other cities, and the vulnerability indexes of ecological, social, and economic subsystems were not significantly different from those of other cities. This was because the development focus of Heilongjiang Province shifted from energy exploitation to heavy industry manufacturing. While developing heavy industry, it increased the proportion of tertiary industry and enriched the industrial structure.

In summary, there were differences in the development of prefecture-level cities in Heilongjiang Province. However, with the implementation of policies, such as economic transformation and revitalization of the old industrial bases in northeast China, the overall vulnerability of cities has been effectively alleviated, urban carrying capacity has been increased, resource allocation of different cities has been balanced, and the urban development gap has gradually narrowed.

\subsection{Analysis of dynamic evolution of urban vulnerability}

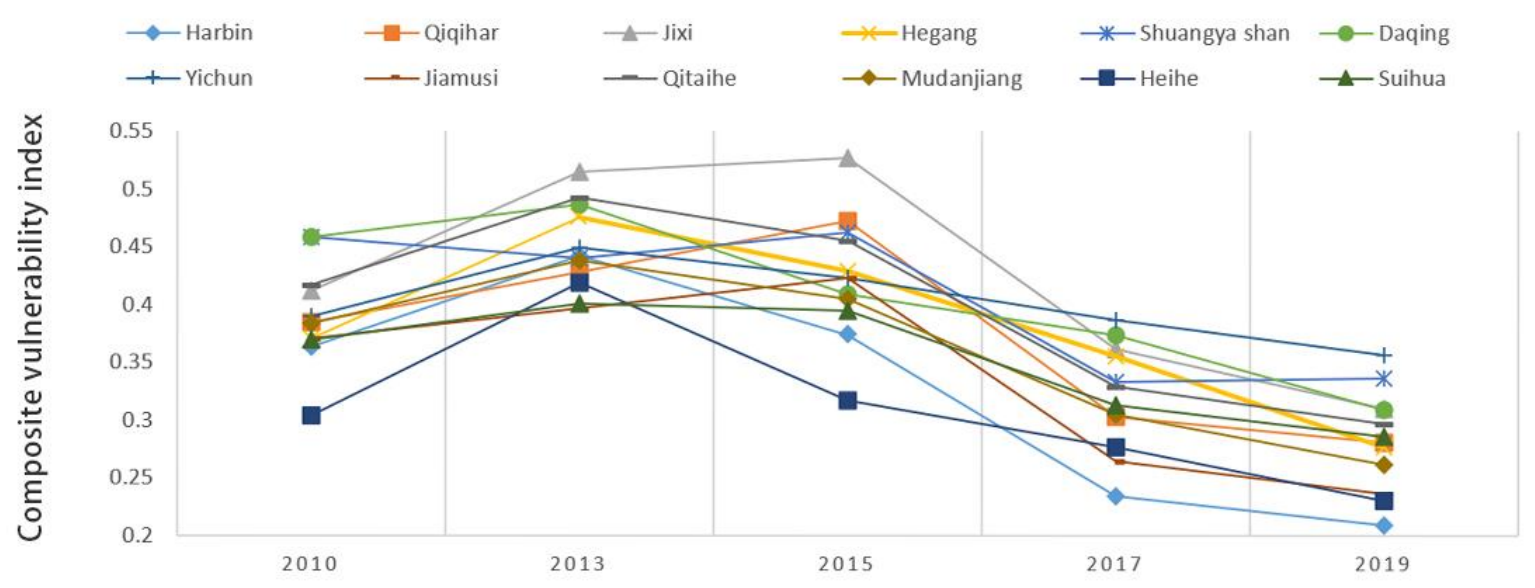

Figure 3 Trends in urban vulnerability indexes from 2010 to 2019. Source: Authors, 2021.

Table 4 Moran's Index of urban vulnerability 2010-2019. Source: Authors, 2021.

\begin{tabular}{|c|c|c|c|c|c|}
\hline Year & 2010 & 2013 & 2015 & 2017 & 2019 \\
\hline P-Value & 0.0030 & 0.0650 & 0.0070 & 0.1200 & 0.1480 \\
\hline Z scores & 2.9424 & 1.5648 & 3.0301 & 1.2436 & -1.0550 \\
\hline Moran'I & 0.2253 & 0.0464 & 0.2577 & 0.0649 & -0.2675 \\
\hline
\end{tabular}


Based on changes in the vulnerability indexes of each city (Figure 3), the vulnerability indexes of the city as a whole showed a declining trend over time. From 2010 to 2013, the comprehensive vulnerability of all cities, except Shuangyashan City, increased significantly. From 2013 to 2019, the comprehensive vulnerability index of all cities decreased, except for Shuangyashan City-its index increased slightly in 2015. From 2017 to 2019, the vulnerability index of cities in the study region remained below 0.4, indicating that the vulnerability of cities has improved significantly in recent years.

GeoDa software was used to conduct a spatial autocorrelation analysis of comprehensive urban vulnerability in the study area from 2010 to 2019 (Table 4). The years 2010 and 2015 were statistically significant $(P<0.01)$ based on $Z$ scores, with confidence levels greater than $99 \%$. However, the rest of the years were not statistically significant. Therefore, the analysis of Moran's I in 2010 and 2015 showed that urban vulnerability exhibited a positive spatial correlation. Urban vulnerability in the study area generally increased in 2013, with most cities increasing to a moderate vulnerability status. After 2015, urban vulnerability decreased, and the vulnerability gap between cities narrowed, showing a balanced spatial distribution across the province. Table 4 shows that the spatial distribution of urban vulnerability was gradually balanced and discrete, indicating that urban revitalization and transformation development of the old industrial bases in Heilongjiang Province was quite effective.

\subsection{Evolution analysis of subsystem vulnerability}

(a)Resource vulnerability

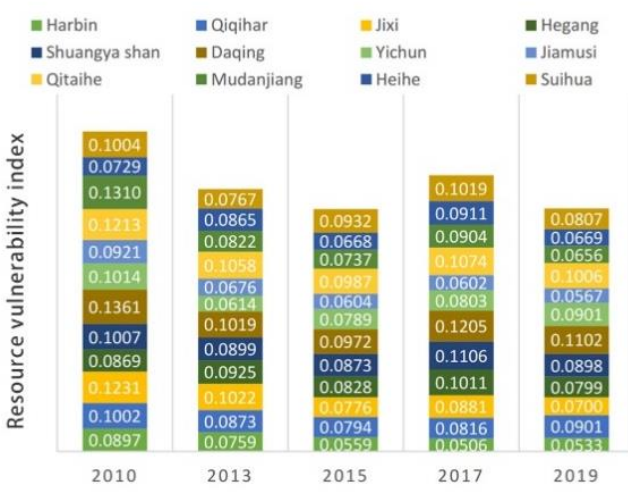

(c)Social vulnerability

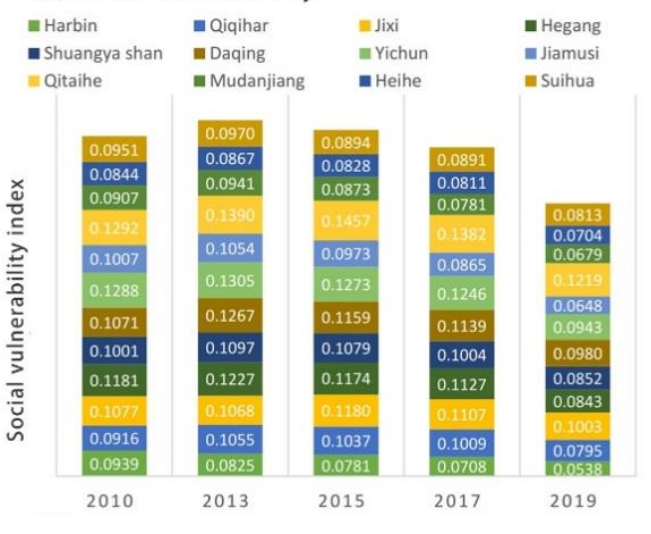

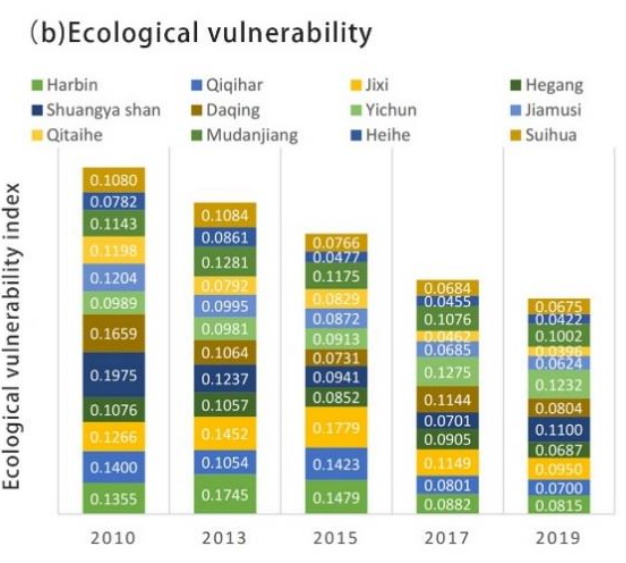

(d)Economic vulnerability

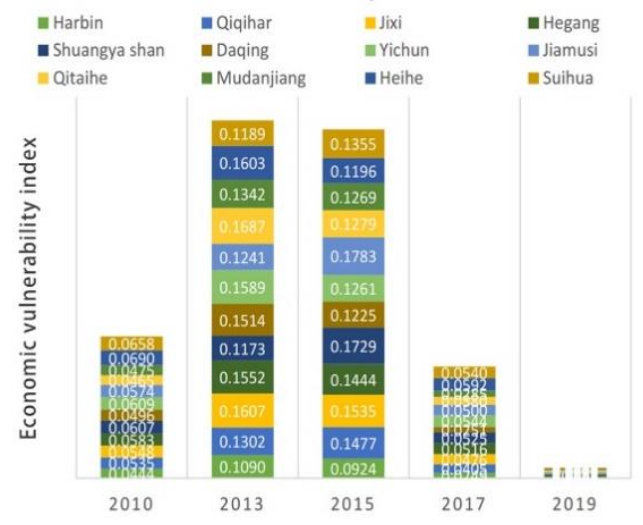

Figure 4 Changes in subsystem vulnerability indexes from 2010 to 2019. Source: Authors, 2021. 


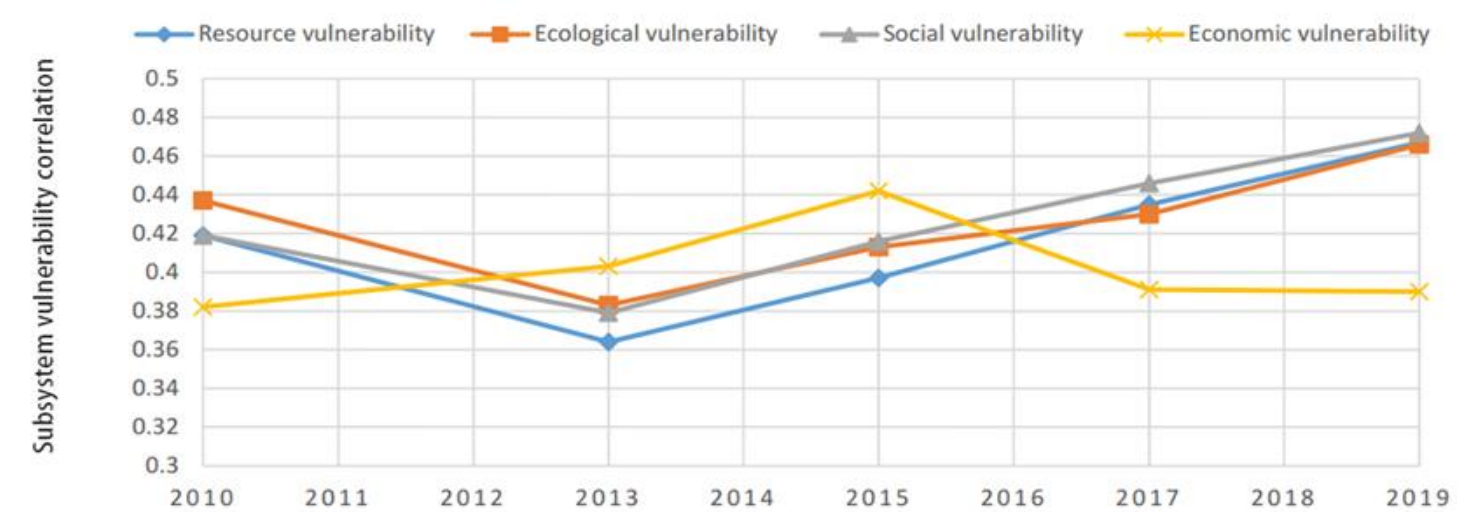

Figure 5 Changes in the degree of subsystem vulnerability correlation from 2010 to 2019. Source: Authors, 2021.

In the study area, the vulnerability of the urban resource subsystem fluctuated and declined. Figure 4 shows that the vulnerability of the urban resource subsystem was related to national regulation and resource demand, such as water, electricity, and energy consumption per unit GDP. The vulnerability of the ecological subsystem constantly decreased because the national government enacted a policy of green development and ecological priority, and local governments have actively conducted several projects, such as protecting the ecological environment and reducing waste discharge. Using ecological environmental protection as the premise for urban development, the problem of ecological environmental pollution caused by the excessive development of heavy industry has been alleviated to a large extent. Furthermore, investment in environmental protection has increased and repaired and protected the existing ecological environment.

Under the policy of green development enacted by the state, Heilongjiang Province, which has heavy industry as its main industry, has suffered an impact on its economy to a degree. Although the ecological vulnerability has decreased, the vulnerability of its economic subsystem has increased significantly. During this period, the urban economic transformation was unsuccessful because it mainly relied on the energy industry and heavy industry manufacturing to drive urban development. However, after 2017, the vulnerability of the urban economy in Heilongjiang Province decreased significantly, primary and secondary industries have steadily increased, and the development of tertiary industry has also significantly improved. From 2010 to 2013, the vulnerability of the social subsystem increased slightly and then declined steadily and was closely related to governmental investment in infrastructure construction and further improvement of the social security system.

The grey correlation degree analysis of the vulnerability of each urban subsystem and the comprehensive urban vulnerability index from 2010 to 2019 (Figure 5) showed that the degree of correlation between urban vulnerability and ecological subsystems was the highest in 2010 , and the degree of correlation between the vulnerability of the economic subsystem and comprehensive urban vulnerability was the highest in 2013 and 2015. In 2017 and 2019, the overall vulnerability of the city, the subsystems, and the social subsystem decreased. Therefore, the correlation between the comprehensive vulnerability of the city and the social subsystem was the highest.

\section{Conclusion}

This study analyzed the comprehensive vulnerability, spatiotemporal dynamic evolution, and vulnerability of the four subsystems of resources, ecology, economy, and society and drew the following conclusions: (1) From a spatial perspective, the pattern of the urban vulnerability of Heilongjiang Province in 2015 showed a cluster of high-vulnerability areas. Overall urban vulnerability decreased and tended to be evenly distributed. This showed that the strategies to revitalize the old industrial bases in northeast China were 
effective, and the urban development potential of Heilongjiang Province improved. In the future, the reform policy of the old industry should continue to follow the current urban development model, such as protecting the urban ecological environment and strengthening urban economic transformation.

(2) From a temporal perspective, the urban vulnerability of Heilongjiang Province exhibited an upward trend from 2010 to 2013 and a gradual decline from 2013 to 2019, when resource vulnerability, ecological vulnerability, and social vulnerability all declined steadily. However, economic vulnerability showed an upward and then downward trend. The fluctuating trend of economic vulnerability showed that the economic development and transformation of Heilongjiang Province had an effect. In the future, we should continue to adjust the industrial structure, increase investment in science and technology, develop hightech industries, and reduce economic vulnerability.

(3) The correlation between urban vulnerability and ecological vulnerability in Heilongjiang Province was the highest in 2010. The correlation between urban vulnerability and economic vulnerability was the highest in 2013-2015, and then the highest correlation shifted to social vulnerability. Although urban social security and infrastructure construction are steadily increasing, unbalanced and inadequate conditions remain. With urban development, we should strengthen the policy tilt of the social security system and resource allocation, increase the investment share of education and medical care, improve infrastructure construction, and reduce the vulnerability of urban society.

\section{References}

ADGER, HUQ, S., BROWN, K., TO, A., CONWAY, D. \& HULME, M. (2006), "Adger, W. N., (2006), Vulnerability, Global Environmental Change 16 (3), 268-281".

BO, L., ZHI, Y. \& FEI, S. (2015), "Measurement of vulnerability in human-sea economic system based on set pair analysis_A case study of Dalian city", Geographical Research.

FANG, C., WANG, Y. \& FANG, J. (2016), "A comprehensive assessment of urban vulnerability and its spatial differentiation in China", Acta Geographica Sinica, Vol. 026 No. 002, pp. 153-170.

FERDINANDO, VILLAHELENA \& MCLEOD (2002), "Environmental Vulnerability Indicators for Environmental Planning and Decision-Making: Guidelines and Applications", Environmental Management.

HAINING, C., FANG, W. \& FENG, T. (2018), "Evaluation of Urban Vulnerability in Resource-oriented City Based on Entropy Weight and Matter Element Model", Bulletin of Soil and Water Conservation.

HE, L. I. \& ZHANG, P. (2011), "Research Progress and Prospective Applications of Vulnerability Approach under Global Change", Progress in Geography.

LEE, Y. J. (2014), "Social vulnerability indicators as a sustainable planning tool", Environmental Impact Assessment Review, Vol. 44 No. 1, pp. 31-42.

LIN, Z., WEI, W., YU-SHUO, Z., RUI, L. \& DIAN-TING, W. (2014), "The Spatio-Temporal Evolution about Urban Vulnerability on the Northeast Region since Northeast Revitalization", Economic Geography.

MEI, Z., HUAI-LIANG, L. \& LIN, C. (2018), "Vulnerability Assessment of Resource-Based City_—A Case Study of Panzhihua".

TURNER, B., KASPERSON, R. E., MATSON, P. A., MCCARTHY, J. J. \& SCHILLER, A. (2003), "A framework for vulnerability analysis in sustainability science", Proceedings of the National Academy of Sciences, Vol. 100 No. 14 , pp. 8074-8079.

VOGEL, C. (2004), "Vulnerability and global environmental change", AVISO (Ottawa, Ont.), Vol. 131-8.

WANG, Y., FANG, C., ZHANG, Q. \& ZHOU, Y. Y. (2013), "Progress and prospect of urban vulnerability", Progress in Geography, Vol. 32 No. 5, pp.

WEI-KE, C. (2020), "Temporal and spatial dynamic evolution and key fragility factor analysis of urban vulnerability: taking Henan Province for example", Urban Problems.

YANZHONG, L., GAIFENG, S., YONG, C., ZUO, Z. \& XIAONAN, Z. (2020), "Comprehensive Measurement and Evaluation of Vulnerability of Mineral Resource-based Cities", Multipurpose Utilization of Mineral Resources.

YU, G. (2014), "VULNERABILITY ASSESSMENT OF RESOURCES-BASED CITIES BASED ON PSE-C MODEL", Resources \& Industries.

ZHANG, X. R., CHENG, L. \& WANG, Z. B. (2015), "Simulation and Prediction on the Dynamic Evolution of Urban Vulnerability", China Population, Resources and Environment. 